\title{
Pesticide transport and transformation modeling in soil column and groundwater contamination prediction
}

\author{
*S. A. Mirbagheri; S. A. Hashemi Monfared \\ Department of Civil Engineering, K. N. Toosi University of Technology, Tehran, Iran \\ Received 13 August 2008; $\quad$ revised 8 October 2008; accepted 26 October 2008; available online 1 March 2009
}

\begin{abstract}
Pesticide transport and transformation were modeled in soil column from the soil surface to groundwater zone. A one dimensional dynamic mathematical and computer model is formulated to simulate two types of pesticides namely 2,4-dichlorophenoxy acetic acid and 1,2-dibromo 3-chloro propane in soil column. This model predicts the behavior and persistence of these pesticides in soil column and groundwater. The model is based on mass balance equation, including convective transport, dispersive transport and chemical adsorption in the phases such as solid, liquid and gas. The mathematical solution is obtained by finite difference implicit method. The model was verified with experimental measurements and also with analytical solution. The simulation results are in good agreement with measured values. The major findings of this research are the development of the model which can calculate and predict the concentration of pesticides in soil profiles, as well as groundwater after 4, 12, 31 days of pesticide application under steady state and unsteady water flow condition. With the results of this study, the distribution of various types of pesticides in soil column to groundwater table can be predicted.
\end{abstract}

Keywords: Water movement, finite difference, soil system, numerical method, pollution

\section{INTRODUCTION}

There is evidence that chemicals applied to the soil surface may be transported rapidly to groundwater passing the unsaturated soil zone (Johnson et al., 1995). Toxic materials especially pesticides are being used for many purposes in the environment. These substances are adsorbed in soil environment through natural processes occurring in soil water plant relationships. Adsorption is one of the most important factors that affects fate of pesticide in soils and determines their distribution in the soil/water environment (Kah and Brown, 2007). Concern about the environmental impact of repeated pesticide use has prompted research into the environmental fate of these agents, which can emigrate from treated fields to air, other land and waterbodies (Arias-Estevez et al., 2008). Two types of pesticides namely 2,4-dichlorophenoxy acetic acid (2, 4-D) and 1, 2 dibromo 3chloro propane (DBCP) in soil column were considered. The positive attributes of DBCP as a nematocide are as follows: 1) it is less volatile than many of the other soil fumigants of the time period; 2) it remains active in the soil for a long

\footnotetext{
\*Corresponding Author Email: mirbagheri@kntu.ac.ir
}

Tel.: +9821 137 4357; Fax:+9821 88035516 time; 3) it is very effective in killing nematodes and 4) it does not penetrate the roots of plants. The negative attributes of DBCP as a nematocide are that 1) it is relatively mobile in soils with high groundwater recharge rates, 2) it is fairly persistent, 3) there is strong evidence that it causes sterility in human males and 4) it is likely to be carcinogenic (Babich and Davis, 1981).

Several studies have utilized laboratory-scale columns filled with compacted municipal refuse in landfills (Qasim and Burchinal, 1970; Rovers and Farquhar, 1973; Walsh and kinman, 1979). Mc Creanor and Reinhart (2000) developed a mathematical model for the leachate of landfill in the United States. A huge volume of annually precipitation infiltrates in to the ground surface of various catchment's areas in the world and produces extensive water resources under the ground surface (Bodaghpour et al., 2007). After precipitation and infiltration of surface water to soil, toxic materials coming to groundwater and contaminate this region. Therefore, studying pollutant behavior of pesticides in soil column is an important problem. In recent years, water and pollution movement in soil were modeled. Some of them were based on movement of 
soluble and washed samples in soil column. Others were the result of changing concentration of toxic materials in agricultural soils. The pesticide transport and transformation processes in soil column under transient flow condition are complex. Several complicating factors which control transport of different types of pesticides include: a) pore water velocity, b) evaporation and transformation fluxes, c) concentration gradient and d) seasonal rise and fall of the water table. In general, contamination of soil and groundwater by pesticides are the result of mass flow and concentration gradient. Physical, chemical and microbial factors affect the process. Selenium transport and transformation in soil column and groundwater contamination was studied with other researchers (Mirbagheri, 1995; Mirbagheri and Kazemi, 2008; Mirbagheri et al., 2008). Some researches provided a model for predicting the fate of nonvolatile pesticides (Wagenet and Huston, 1986; 1987; Wagenet et al.,1989). In many cases, they considered a distribution coefficient for this case (Deeley et al., 1991). Developing models with molecular diffusion and other important factors have been done by other researchers (Jury et al., 1983; Kalita et al., 1998). Kloos (1983) investigated pesticide in drinking water wells in Fresno and other communities in the Central Valley of California. Stevenson et al. (1997) considered the influence of pesticides in groundwater pollution. Leaching pesticides from biological wastes modeled by others (Taube et al., 2002; Vorkamp et al., 1997; 1999). DBCP and 2,4-D effects in soil column in unsaturated zone and in groundwater were studied comparing with experimental works (Loague et al., 1996; 1998). Models for long-term fate of pesticides in soils is considered in recent years (Scholtz and Bidleman, 2007). Muller et al. (1998) investigate a method for cleaning water polluted with pesticides. Also a study was carried out on the sorption of the sparingly watersoluble pesticide in various types of soil with different levels of organic matter by Zbytniewski and Buszewski (2002). Also USDA, forest service, forest health protection (2006) performed experimental works on 2, 4-D transport in soil column. This paper presents a model which considers all phases of transport and transformation of pesticide in soil column.

\section{MATERIALS AND METHODS}

Water flow model formulation

Obviously, it is not possible to unequivocally validate the models already used to predict subsurface fluid flow and solute transport (Oreskes et al., 1994).

Water flow is calculated using a one-dimensional finite difference solution to the soil-water flow equation:

$\frac{\partial h}{\partial t} C(\theta)=\frac{\partial}{\partial z}\left[K(\theta) \frac{\partial H}{\partial z}\right]-u(z, t)$

Where, $h$ is a soil water pressure head (mm); $\theta$ is volumetric water content $\left(\mathrm{m}^{3} / \mathrm{m}^{3}\right)$; $t$ is time (day); $H$ is hydraulic head $(h+z) ; z$ is soil depth $(\mathrm{mm}) ; k$ is hydraulic conductivity ( $\mathrm{cm} /$ day); $C(\theta)=\frac{\partial \theta}{\partial h}$ is differential water capacity and $u$ is a sink term representing water loss by transpiration.

There is a two part function that describes the general shape of $\theta(h)$ relationships (Hutson and Cass, 1987).

$\begin{array}{lll}h=\frac{\left(1-\theta / \theta_{S}\right)^{1 / 2}\left(\theta_{i} / \theta_{S}\right)^{-b}}{\left(1-\theta_{i} / \theta_{S}\right)^{1 / 2}} & \text { for } & h_{i}<h<0 \\ h=a\left(\theta / \theta_{S}\right)^{-b} & \text { for } & -\infty<h<h_{i}\end{array}$

Where, $h_{i}=a[2 b /(1+2 b)]^{-b}$ and $\theta_{i}=2 b \theta_{S} /(1+2 b)$ is the point $h_{i}, \theta_{i}$ intersection of the two curves, $\theta_{s}$ is water content at saturation, $a$ and $b$ are constants. The two curves are exponential and parabolic for dry and saturated soil, respectively. Similarly the equations for hydraulic conductivity can be described as a function of soil water pressure head. When soil water pressure head is greater than $h_{i}$, the following equation is used to calculate hydraulic conductivity:

$K(\theta)=K_{S}\left(\theta / \theta_{S}\right)^{2 b+2+p}$

Where, $K_{s}$ is hydraulic conductivity at saturation $(\theta)$ and $P$ is pore water interaction parameter. When soil water pressure head is less than $h_{i}$, the equation for the calculation of hydraulic conductivity is:

$K=K_{S}(a / h)^{2+(2+p) / b}$

Solving Eq. 1 using finite difference techniques provides estimated values at each depth, node used in differencing equations. Water contents are calculated using Eq. 2 and water flux densities $(q)$ are calculated over each depth interval using darceys equation $(q=$ $K(\theta) \Delta H / \Delta Z$ ). Finally, the values of $q$ are then used to 
estimate pesticide transport in the soil profile.

\section{Pesticide transport model formulation}

Movement of a soluble and volatile pesticide in soil column is described in three shapes:

- Chemical transportation in liquid phase because of liquid concentration gradient;

- Gas transportation because of gas concentration gradient and

- Convection of pesticide can occur as a result of movement of water in response to pore water velocity gradient and gas partial pressure gradient

Thus the transportation of a pesticide is described as:

$$
J_{t}=J_{d l}+J_{c l}+J_{d g}+J_{c g}
$$

Where,

$J_{t}$ : Total transportation of pesticide

$J_{d}$ : Liquid diffusion flux

$J_{c l}$ : Liquid convection flux

$J_{d g}$ : Gas diffusion flux

$J_{c g}:$ Gas convection flux

Movement in liquid phase

When, flow is in a porous media, $J_{d l}$ is:

$$
J_{d l}=-D_{p}(\theta, q) d C_{l} / d Z
$$

Where, $C_{l}$ is the concentration in liquid phase (mg/ L) and $D_{p}(\theta)$ is the molecular diffusion coefficient decribed as below:

$$
D_{p}(\theta)=D_{o l} \times a e^{-b \theta}
$$

Where, $D_{o l}$ is molecular dispersion coefficient in liquid phase ( $\mathrm{cm}^{2} /$ day); $a$ and $b$ are constant. The liquid convection flux $J_{c l}$ is:

$$
J_{c l}=-\theta D_{M}(q) \frac{d C_{l}}{d Z}+q C_{l}
$$

Where, $q$ is water flux ( $\mathrm{cm}^{3} / \mathrm{cm} /$ day) and $D_{M}(\theta, q)$ is the hydrodynamic dispersion coefficient and is obtained as follow:

$$
D_{M}(\theta, q)=\lambda|V|
$$

Where, $V$ is the velocity of water flux (cm/day) and $\lambda$ is propagation coefficient generally considerd as:

$$
2 m m<\lambda<80 m m
$$

Movement in gas phase

Gas diffusion flux in porous media results from the following processes:

$J_{d g}=-D_{g}(\varepsilon) \times d C_{g} / d Z$

Where, $D_{g}$ is the average gas diffusion coefficient $\left(\mathrm{cm}^{2} /\right.$ day) in gas phase and is:

$D_{g}(\varepsilon)=D_{o g} \times \gamma(\varepsilon)$

Where, $\varepsilon$ are voids including gas and calculated as: $\varepsilon=\theta_{s}-\theta$

And $D_{o g}$ is the gas diffusion coefficient in air and $\gamma(\varepsilon)$ is a coefficient:

$\gamma(\varepsilon)=(\varepsilon)^{\frac{10}{3}} / \theta_{s}^{2}$

Changing in soil water content, barometric pressure and temperature may cause air flow to the soil column. Since changes are periodic, it is possible to simulate these effects with increasing in gas diffusion coefficient.

For volatile composes liquid and gas concentration are related with Henry law.

$C_{g}=K_{H} C_{l}$

Where, $K_{H}$ is the Henry coefficient.

Therefore, transports of pesticide in phase can be calculated as:

$J_{D l}+J_{c l}+J_{d g}=-D_{p} \frac{d C_{l}}{d Z}-$

$\theta D_{M}(q) \frac{d C_{l}}{d Z}-D_{o g} K_{H} \frac{d C_{l}}{d Z}+q C_{l}$

More pesticide transports are in steady-state water flow condition. In this condition, water content $(\theta)$ and water flux $(q)$ are variable with time and depth.

Mass balance equation

$\partial C_{t} / \partial t=-\left(\partial J_{t} / \partial Z\right) \pm \Phi$

Where, $\Phi$ is source/sink of pesticide. 
When a volatile pesticide in adsorbed solution phase contacts with soil, the concentration of pesticide in solution is:

$$
C_{t}=\theta C_{l}+q C_{s}+\varepsilon C_{g}
$$

Where, $\rho$ is the soil bulk density $\left(\mathrm{kg} / \mathrm{m}^{3}\right)$ and $\mathrm{C}_{\mathrm{s}}$ is the concentration of pesticide $(\mathrm{mg} / \mathrm{L})$. Assuming that the pesticide adsorption is sudden and reversible then:

$C_{s}=K_{d} C_{l}$

Where, $K_{d}$ is the distribution coefficient $\left(\mathrm{m}^{3} / \mathrm{kg}\right)$. Substituting this equation in Eq. 16:

$$
C_{t}=C_{l}\left(\theta+\rho K_{d}+\varepsilon K_{H}\right)
$$

Now all parameters of Eq. 15 can be determined, therefore:

$$
\begin{aligned}
& \frac{\partial C_{l}}{\partial t}\left(\theta+\rho K_{d}+\varepsilon K_{H}\right)= \\
& \frac{\partial}{\partial Z}\left[\theta D(\theta, q) \frac{\partial C_{l}}{\partial Z}-q C_{l}\right] \pm \Phi
\end{aligned}
$$

\section{Solution method}

Eq. 20 may discrete with non-equal steps like Bersler method. In point $i$ and time $j$ :

$$
\begin{aligned}
& \left(\frac{\partial\left(\theta C_{l}\right)}{\partial t}\right)=\left(\theta_{i}^{j+1} \times C_{i}^{j+1}-\theta_{i}^{j} \times C_{i}^{j}\right) / \Delta t \\
& \left(\rho K_{d} \frac{\partial C}{\partial t}\right)=\rho K_{d}\left(C_{i}^{j+1}-C_{i}^{j}\right) / \Delta t \\
& K_{H} \frac{\partial\left(\varepsilon C_{l}\right)}{\partial t}=K_{H}\left(\varepsilon_{i}^{j+1} \times C_{i}^{j+1}-\varepsilon_{i}^{j} C_{i}^{j}\right) / \Delta t \\
& \frac{\partial}{\partial Z}\left[\theta D(\theta, q) \frac{\partial C}{\partial Z}\right]=\left[D_{i-\frac{1}{2}}^{j+\frac{1}{2}} \times \theta_{i-\frac{1}{2}}^{j+\frac{1}{2}}\right. \\
& \left(C_{i-1}^{j+1}+C_{i-1}^{j}-C_{i}^{j+1}-C_{i}^{j}{ }^{j}\right) / \Delta Z_{1} \\
& -D_{i+\frac{1}{2}}^{j+\frac{1}{2}} \times \theta_{i+\frac{1}{2}}^{j+\frac{1}{2}}\left(C_{i}^{j+1}+C_{i}^{j}-C_{i+1}^{j+1}-C_{i+1}^{j}\right) \\
& / \Delta Z_{2}{ }^{j} / \Delta Z_{3}
\end{aligned}
$$

$$
\frac{\partial}{\partial Z}(q C)=\beta_{1} q_{i-\frac{1}{2}}^{j+\frac{1}{2}}\left(C_{i-1}^{j}+C_{i-1}^{j+1}\right) / \Delta Z_{3}-
$$$$
\beta_{2} q{ }_{i+\frac{1}{2}}^{j+\frac{1}{2}}\left(C_{i}^{j}+C_{i}^{j+1}\right) / \Delta Z_{3}
$$$$
-\beta_{3} q_{i+\frac{1}{2}}^{j+\frac{1}{2}}\left(C_{i+1}^{j}+C_{i+1}^{j+1}\right) / \Delta Z_{3}+
$$$$
\beta_{4}{ }_{i-\frac{1}{2}}^{j+\frac{1}{2}}\left(C_{i}^{j}+C_{i}^{j+1}\right) / \Delta Z_{3}
$$

Where,

$$
\begin{array}{ll}
\beta_{1}=1, \beta_{4}=0 & \text { When } \quad q_{i-\frac{1}{2}}>0 \\
\beta_{1}=0, \beta_{4}=1 & \text { When } \quad q_{i-\frac{1}{2}}<0 \\
\beta_{2}=1, \beta_{3}=0 & \text { When } \quad q_{i+\frac{1}{2}}>0 \\
\beta_{2}=0, \beta_{3}=1 & \text { When } \quad q_{i+\frac{1}{2}}<0
\end{array}
$$

Replacing above contents in Eq. 20:

$\left(\theta_{i}^{j+1} C_{i}^{j+1}-\theta_{i}^{j} C_{i}^{j}\right) / \Delta t+K_{h}\left(\varepsilon_{i}^{j+1} C_{i}^{j+1}-\varepsilon_{i}^{j} C_{i}^{j}\right) / \Delta t+$

$$
\begin{aligned}
& \rho K_{d} \frac{\left(C_{i}^{j+1}-C_{i}^{j}\right)}{\Delta t}=\frac{D_{i-\frac{1}{2}}^{j+\frac{1}{2}}}{\Delta Z_{1} \Delta Z_{3}}\left(C_{i-1}^{j+1}+C_{i-1}^{j}-C_{i}^{j+1}-C_{i}^{j}\right)- \\
& \frac{{ }^{j+\frac{1}{2}}}{\Delta Z_{2} \Delta Z_{3}}\left(C_{i}^{j+1}+C_{i}^{j}-C_{i+1}^{j+1}+C_{i+1}^{j}\right)+
\end{aligned}
$$

$$
\begin{aligned}
& \beta_{1}{ }_{i-\frac{1}{2}}\left(C_{i-1}^{j}+C_{i-1}^{j+1}\right) / \Delta Z_{3}-\beta_{2} q_{i+\frac{1}{2}}\left(C_{i}^{j}+C_{i}^{j+1}\right) / \Delta Z_{3} \\
& -\beta_{3}{ }_{i-\frac{1}{2}}\left(C_{i+1}^{j}+C_{i+1}^{j+1}\right) / \Delta Z_{3}+\beta_{4}{ }_{i-\frac{1}{2}}\left(C_{i}^{j}+C_{i}^{j+1}\right) / \Delta Z_{3}+\Phi_{i}^{j}
\end{aligned}
$$

If define new parameters like following:

$$
A B_{i}=D_{i-\frac{1}{2}}^{j+\frac{1}{2}} / \Delta Z_{1} \Delta Z_{3}
$$




$$
\begin{aligned}
& B B_{i}=D_{i-\frac{1}{2}}^{j+\frac{1}{2}} / \Delta Z_{2} \Delta Z_{3} \\
& D B_{i}=q_{i+\frac{1}{2}} / \Delta Z_{3} \\
& C B_{i}=q_{i-\frac{1}{2}} / \Delta Z_{3}
\end{aligned}
$$

Then:

$C_{i-1}^{j+1}\left(-A B_{i}-\beta_{1} C B_{i}\right)+C_{i}^{j+1}$

$\left(\frac{\theta_{i}^{j+1}}{\Delta t}+\frac{\rho K_{d}}{\Delta t}+\frac{\varepsilon_{i}^{j+1}}{\Delta t}+A B_{i}+B B_{i}+\beta_{2} D B_{i}-\beta_{4} C B_{i}\right)+$

$C_{i+1}^{j+1}\left(-B B_{i}-\beta_{3} D B_{i}\right)=$

$C_{i-1}^{j}\left(A B_{i}+\beta_{1} C B_{1}\right)+C_{i}^{j}$

$\left(\frac{\theta_{i}^{j+1}}{\Delta t}+\frac{\rho K_{d}}{\Delta t}+\frac{\varepsilon_{i}^{j+1}}{\Delta t}-A B_{i}-B B_{i}-\beta_{2} D B_{i}+\beta_{4} C B_{i}\right)$

$+C_{i+1}^{j}\left(B B_{i}-\beta_{3} D B_{i}\right)$

The general shape of this equation is:

$$
A_{i} C_{i-1}^{j+1}+B_{i} C_{i}^{j+1}+C C_{i} C_{i+1}^{j+1}=D_{i}
$$

Where, $A_{i}, B_{i}$ and $C C_{i}$ are constant in each time step. This equation may be solved with one of the solution methods for three diagonal matrixes (Fig. 1).

\section{Upper and lower boundary condition}

The boundary conditions for solute and water flux are not always the same algebraic sign within each time interval since water is evaporated from the soil surface while pesticide accumulation. For example, water in each time step may be evaporated from soil surface. Upper bound needs to be defined for zero flux, infiltration and evaporation.

For zero flux, $C_{1}^{j}=C_{w}, q_{1+1 / 2}^{j+1 / 2}=0$ and $D_{1+1 / 2}^{j+1 / 2}=0$. In infiltration stage $C_{1}^{j}=C_{w}$ and $D_{1+1 / 2}^{j+1 / 2}=0$ where, $C_{w}$ is the pesticide infiltration in water and pesticide flux that is in the soil column is $q_{1+1 / 2}^{1+1 / 2}=C_{w} \Delta t$ and in evaporation stage from soil surface, $C_{1}^{j}=0$ and $q_{1+1 / 2}^{j+1 / 2}=0$

Lower bound needs to be defined for zero flux, unit hydraulic gradient and constant water head. In point $k, q_{k+1 / 2}^{j+1 / 2}=C_{w} \Delta t, D_{k-1 / 2}^{j+1 / 2}=0$ and $C_{k}=0$.

If $C_{g w}$ is the groundwater surface then $D_{k-1 / 2}^{j+1 / 2}=0$ and concentration in point $k$ is equal to $C_{k}=C_{g w}$.

\section{Direction of water flux}
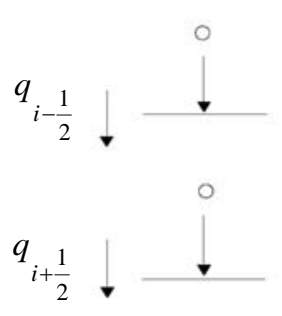

○
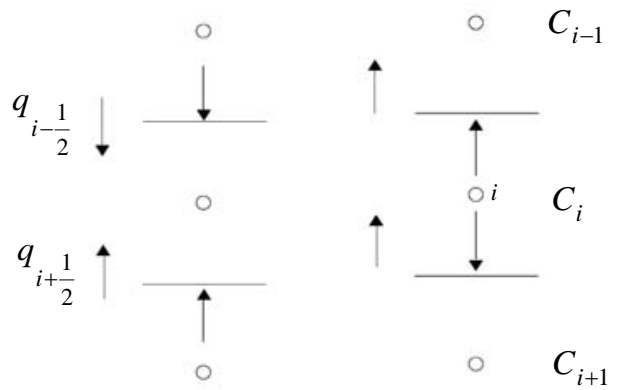

Fig. 1: Pesticide movement in soil layers with water flux

\section{Model application}

The model was applied to simulate the transport and transformation of DBCP concentration in soil depth. The selected physico-chemical data for panochi soil measured by Leachm (Wagenet et al., 1989) and shown in Table 1 and 2 was used for the model calibration and verification. The data is collected for the parameters such as hydraulic conductivity (K), soil water content $(\theta)$ and soil pressure head (h) expressed as functions in Eqs. 2, 3, 4, 5. Other parameters such as saturated hydraulic conductivity $\left(K_{s}\right)$ and a and b constants are summarized in Table 2 for soil depth from 0 to $200 \mathrm{~mm}$ down to $1200-1500 \mathrm{~mm}$. The DBCP data was collected for water flow under steady state and unsteady conditions for $150 \mathrm{~mm}$ irrigation water in a soil plot 6.1 by $6.1 \mathrm{~m}$. The bulk density $(\rho)$ of soil used in this study was $1.4 \mathrm{~kg} / \mathrm{dm}^{2}$ with matric potential of -9 kpa.

\section{RESULTS AND DISCUSSION}

The pesticide simulation model developed for this study facilitates the construction of distribution curves to show the fate of DBCP and 2,4-D in soil column under transient flow conditions. The soil column 
Table 1: Physical and chemical characteristics of soil in the study area

\begin{tabular}{ccccc}
\hline $\begin{array}{c}\text { Organic } \\
\text { matter }(\%)\end{array}$ & $\begin{array}{c}\text { CEC } \\
(\mathrm{mmol} / \mathrm{kg})\end{array}$ & $\begin{array}{c}\text { Clay } \\
(\%)\end{array}$ & $\begin{array}{c}\text { Sand } \\
(\%)\end{array}$ & \multicolumn{1}{c}{$\begin{array}{c}\text { Depth } \\
(\mathrm{mm})\end{array}$} \\
\hline 1.12 & 222 & 14.9 & 35.2 & $0-300$ \\
0.47 & 172 & 33.8 & 49.3 & $300-600$ \\
0.5 & 174 & 33.8 & 46.3 & $600-900$ \\
- & 160 & 34.6 & 42.5 & $900-1200$ \\
- & 160 & 34.6 & 42.5 & $1200-1500$ \\
\hline
\end{tabular}

Table 2: Summary of input data in model

\begin{tabular}{ccccccr}
\hline $\begin{array}{c}\theta_{S} \\
\left(\mathrm{~m}^{3} / \mathrm{m}^{3}\right)\end{array}$ & $\mathrm{a}$ & $\begin{array}{c}\mathrm{K}_{\mathrm{s}} \\
(\mathrm{mm} / \mathrm{d})\end{array}$ & $\mathrm{b}$ & $\begin{array}{c}\mathrm{h} \\
(\mathrm{mm})\end{array}$ & $\begin{array}{c}\rho \\
\left(\mathrm{kg} / \mathrm{dm}^{2}\right)\end{array}$ & \multicolumn{1}{c}{$\begin{array}{c}\text { Depth } \\
(\mathrm{mm})\end{array}$} \\
\hline 0.509 & -100 & 500 & 2.5 & -70 & 1.3 & $0-200$ \\
0.426 & -122 & 50 & 2.5 & -70 & 1.52 & $200-300$ \\
0.426 & -217 & 50 & 3.805 & -70 & 1.52 & $300-600$ \\
0.434 & -252 & 500 & 3.509 & -70 & 1.5 & $600-900$ \\
0.464 & -249 & 60 & 4.374 & -70 & 1.42 & $900-1200$ \\
0.464 & -270 & 60 & 4.213 & -70 & 1.42 & $1200-1500$ \\
\hline
\end{tabular}

assumed to be unsaturated under both conditions. For calibration and validation of model, the data collected by Wagenet et al. (1989) was used. Measured concentration of DBCP ranging from 55 $\mathrm{mg} / \mathrm{L}$ after 4 days of pesticide application to $21 \mathrm{mg} / \mathrm{L}$ in $200 \mathrm{~mm}$ of soil depth after 31 days. The simulated value for DBCP ranging from $52 \mathrm{mg} / \mathrm{L}$ after 4 days of application to $50 \mathrm{mg} / \mathrm{L}$ after 31 days in the same soil depth under steady state water flow condition. But under unsteady water flow condition, measured value of DBCP in $200 \mathrm{~mm}$ soil depth after 4 days was $30 \mathrm{mg} /$ $\mathrm{L}$ and after 31 days decreases to $3 \mathrm{mg} / \mathrm{L}$ and simulated values from $28 \mathrm{mg} / \mathrm{L}$ decrease to $4 \mathrm{mg} / \mathrm{L}$ that means unsteady state water flow conditions prevails in the study area. This is partly due to evaporation and uptake of water by plants. Table 3 shows the summary of measured and simulated data. Figs. 2 to 7 shows that the distribution of DBCP concentrations in soil profile from the surface to $1000 \mathrm{~mm}$ depth follows the same pattern for measured and simulated values under both conditions (steady and unsteady). As the wetted front of soil profile proceed to the bottom of the column, the concentration of pesticide decreases with depth. The simulated values by pesticide model were compared with Loague et al. (1998) and Jurys model (1983) as shown in Table 4. The results are almost the same. Also Fig. 8 shows the comparison of calculated values for DBCP concentrations with the simulated model
Table 3: Comparison of authors's simulated model with measured values by Wagenet et al. (1989)

\begin{tabular}{|c|c|c|c|c|}
\hline \multirow{4}{*}{$\begin{array}{l}\text { Depth } \\
(\mathrm{mm})\end{array}$} & \multicolumn{4}{|c|}{ Water flow } \\
\hline & \multicolumn{2}{|c|}{ Steady } & \multicolumn{2}{|c|}{ Unsteady } \\
\hline & $\begin{array}{c}\text { Measured } \\
\text { con } \\
\text { (mg/L) }\end{array}$ & $\begin{array}{c}\text { Calculated } \\
\text { con } \\
(\mathrm{mg} / \mathrm{L})\end{array}$ & $\begin{array}{c}\text { Measured } \\
\text { con } \\
(\mathrm{mg} / \mathrm{L})\end{array}$ & $\begin{array}{c}\text { Calculated } \\
\text { con } \\
(\mathrm{mg} / \mathrm{L})\end{array}$ \\
\hline & Wagenet & Authors & Wagenet & Authors \\
\hline 0 & 67 & 64 & 0 & 0 \\
\hline 200 & 55 & 52 & 30 & 28 \\
\hline 400 & 43 & 41 & 32 & 32 \\
\hline 600 & 23 & 22 & 10 & 10 \\
\hline 800 & 5 & 5 & 5 & 5 \\
\hline 1000 & 0 & 0 & 0 & 0 \\
\hline 0 & 48 & 63 & 0 & 0 \\
\hline 200 & 33 & 52 & 12 & 15 \\
\hline 400 & 20 & 38 & 14 & 15.5 \\
\hline 600 & 10 & 20 & 7 & 9 \\
\hline 800 & 2 & 4 & 2 & 4.5 \\
\hline 1000 & 0 & 0 & 0 & 0 \\
\hline 0 & 30 & 60 & 0 & 0 \\
\hline 200 & 21 & 50 & 3 & 4 \\
\hline 400 & 10 & 38 & 10 & 12 \\
\hline 600 & 2 & 21 & 6 & 8 \\
\hline 800 & 1 & 3 & 2 & 4 \\
\hline 1000 & 0 & 0 & 0 & 0 \\
\hline
\end{tabular}

Table 4: DBCP concentration in soil depth after 1 day (unsteady-state) and simulation model by Loague et al. (1998) and behavior assessment model by Jury et al. (1983)

\begin{tabular}{|c|c|c|c|c|}
\hline \multirow{4}{*}{$\begin{array}{l}\text { Time } \\
\text { (day) }\end{array}$} & \multirow{4}{*}{$\begin{array}{l}\text { Depth } \\
(\mathrm{mm})\end{array}$} & \multicolumn{3}{|c|}{ Water flow } \\
\hline & & \multicolumn{3}{|c|}{ Unsteady } \\
\hline & & \multicolumn{3}{|c|}{$\begin{array}{c}\text { Calculated } \\
\text { concentration }(\mathrm{mg} / \mathrm{L})\end{array}$} \\
\hline & & Jury & Loague & Authors \\
\hline \multirow{6}{*}{1} & 0 & 0 & 0 & 0 \\
\hline & 200 & 115 & 122 & 110 \\
\hline & 400 & 300 & 302 & 300 \\
\hline & 600 & 100 & 110 & 96 \\
\hline & 800 & 10 & 2 & 10 \\
\hline & 1000 & 0 & 0 & 0 \\
\hline
\end{tabular}


presented by loague et al. (1998). Fig. 9 shows such comparison with BAM model (Jury et al., 1983). Fig. 10 shows the calculated value for 2,4-D concentration in soil depth after 4 days under steady state water flow condition which is different from the concentration of 2,4-D under unsteady state (Fig. 11) because of evaporation of the pesticide at the soil surface and leaching though the soil profile and accumulation in $400 \mathrm{~mm}$ of soil depth. Since the velocity gradient in horizontal and lateral direction of soil column in water flow model is negligible, therefore a one dimensional model for pesticide transport in soil column in vertical direction is dominate in

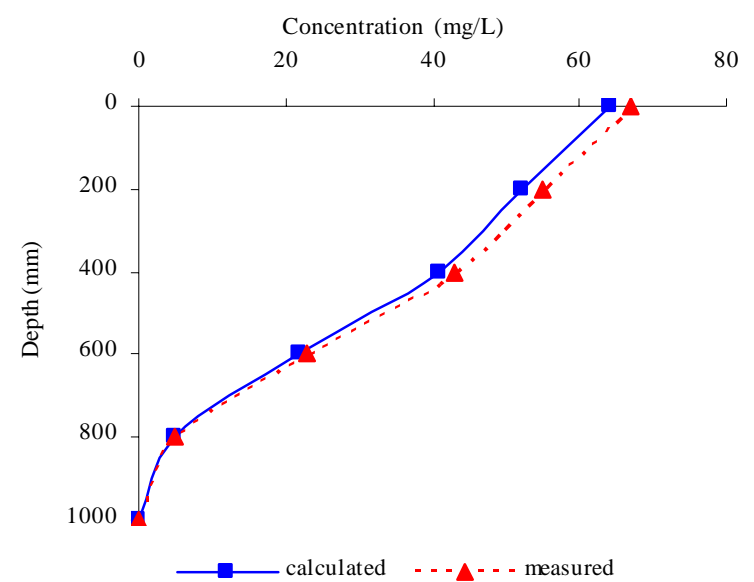

Fig. 2: DBCP concentration in soil depth after 4 days (steadystate) measured by Wagenet et al. (1989)

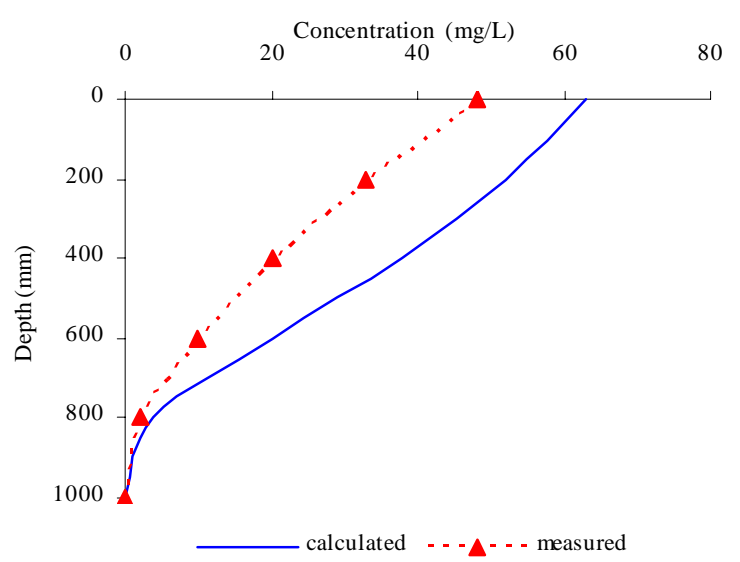

Fig. 4: DBCP concentration in soil depth after 12 days (steadystate) measured by Wagenet et al. (1989) compare to two and three dimensions. A mass balance for concentration of pesticide in vertical direction for two and three dimensional model is almost the same as one dimensional. This is the reason that the reliability of one dimensional model for pesticide transport in soil column is confirmed. Overall, the simulated values for pesticides by pesticide model are in good agreement with measured values.

\section{CONCLUSION}

A one dimensional dynamic mathematical model was developed to simulate the transport and transformation of pesticides concentration namely $\operatorname{BDCP}(1,2$ dibromo

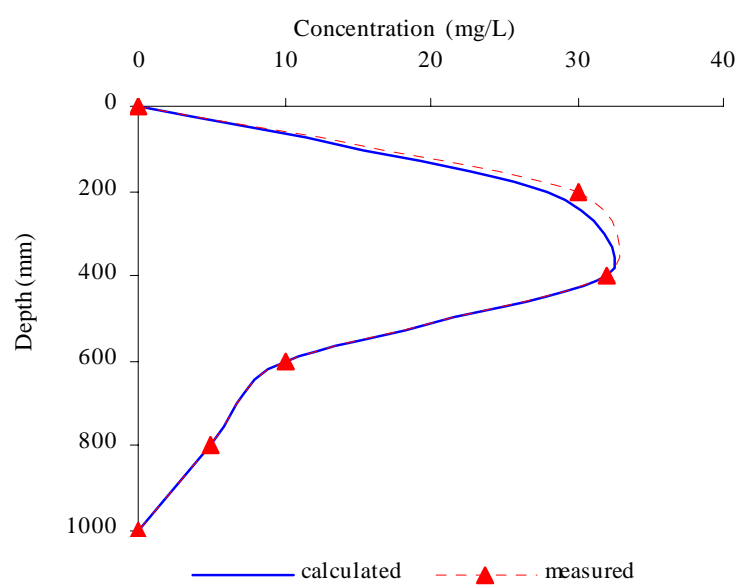

Fig. 3: DBCP concentration in soil depth after 4 days (unsteadystate) measured by Wagenet et al. (1989)

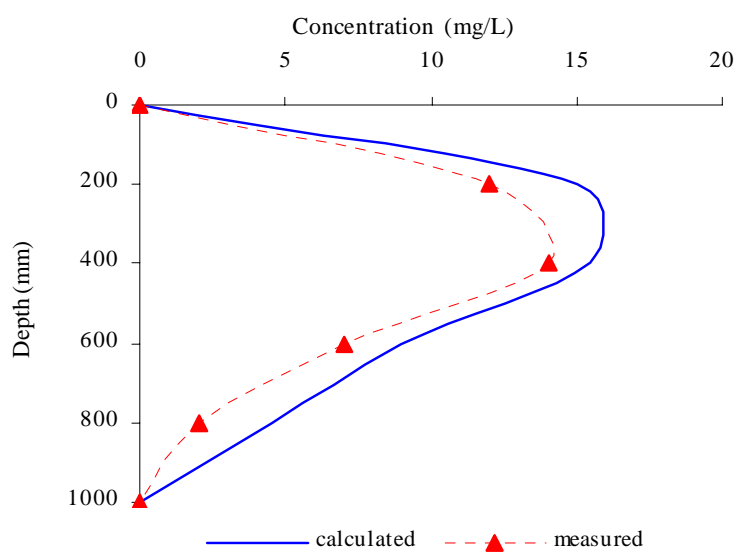

Fig. 5: DBCP concentration in soil depth after 12 days (unsteadystate) measured by Wagenet et al. (1989) 


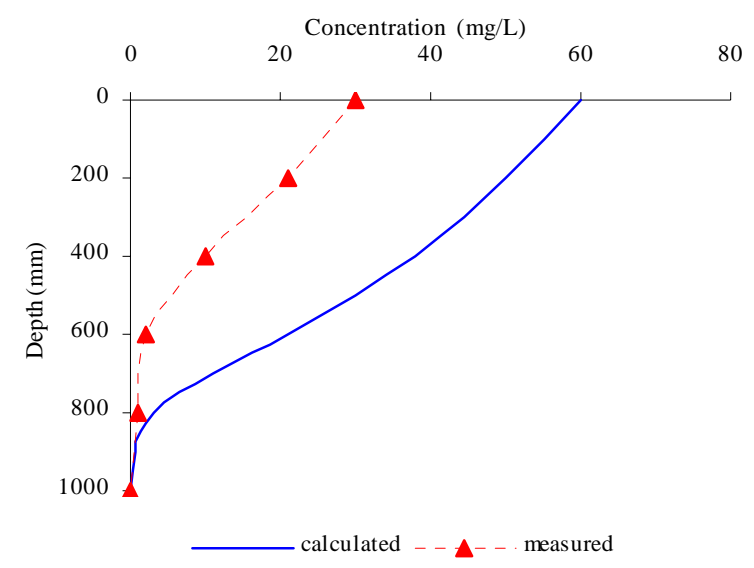

Fig. 6: DBCP concentration in soil depth after 31 days (steadystate) measured by Wagenet et al. (1989)

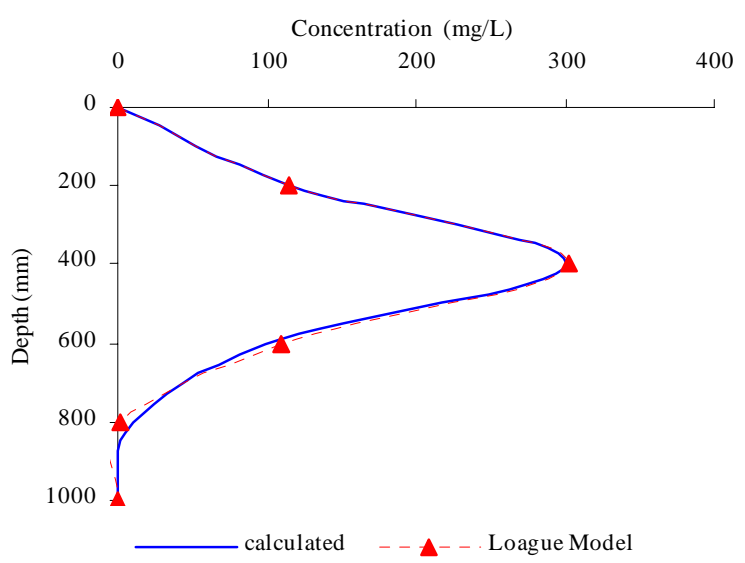

Fig. 8: BDCP concentration in soil depth after 1 day (unsteadystate) and simulation model by Loague et al. (1998)

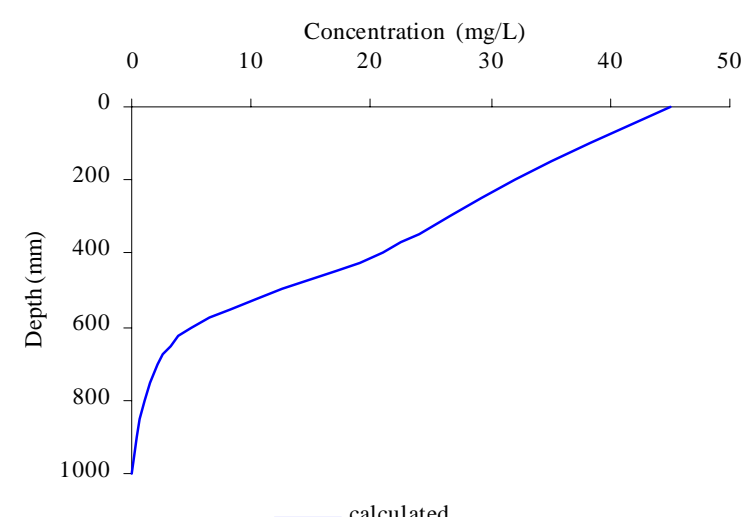

Fig. 10: 2,4-D concentration in soil depth after 4 days (steady-state)

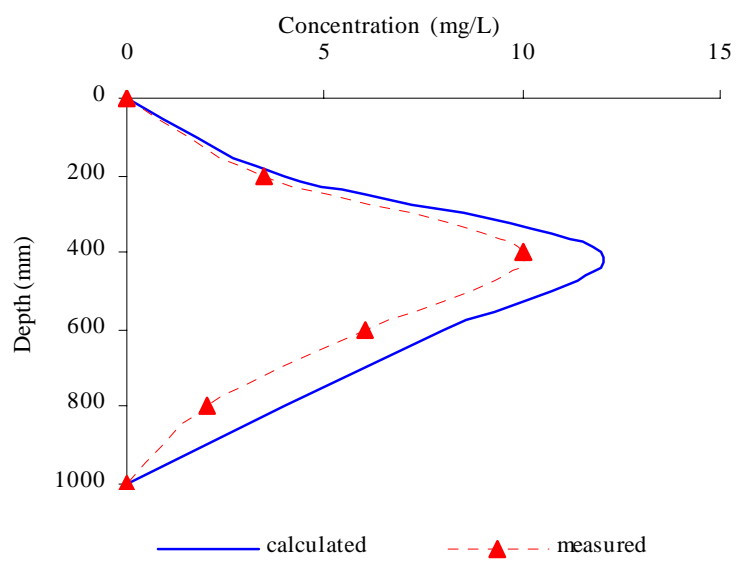

Fig. 7: DBCP concentration in soil depth after 31 days (unsteady state) measured by Wagenet et al. (1989)

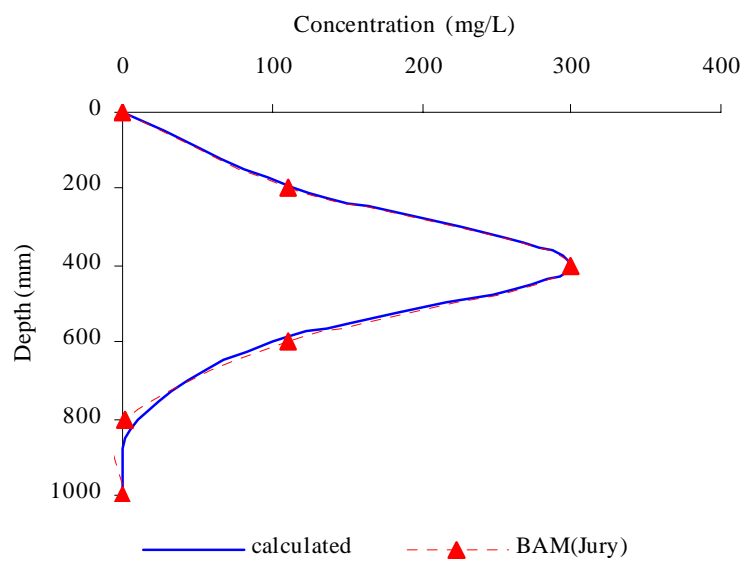

Fig. 9: BDCP concentration in soil depth after 1 day (usteadystate) and behavior assessment model by Jury et al. (1983)

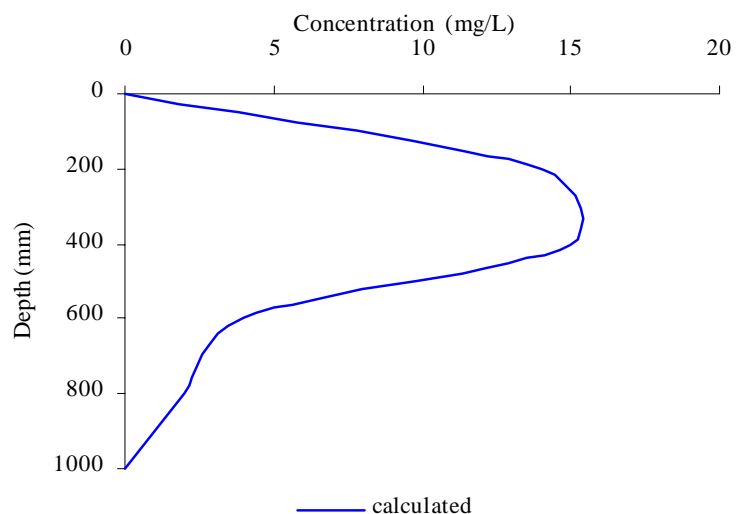

Fig. 11: 2, 4-D concentration in soil depth after 4 days (unsteady-state) 
3chloro propane) and 2, 4-D (2, 4-dichlorophenoxy acetic acid) in soil column. This model is based on the mass balance equation including advective and diffusive transport and chemical adsorption in the phases such as liquid, solid and gas. The solution obtained by a finite difference cranck nickolson method provides for a temporal and spatial description of the DBCP and 2, 4-D in soil column. The model was calibrated and confirmed using data collected by Wagenet et al. (1989). The model also was compared with analytical solution, Jurys and Loagues models. The simulated results are in good agreement with measured values. The model is a useful tool and allows to look well in to the future to use pesticides in agricultural soils and consider alternative management strategies.

\section{REFERENCES}

Arias-Estevez, M.; Lopez-Periago, E.; Martinez-Carballo, E.; Simal-Gandara, J.; Mejuto, J. C.; Garcia-Rio, L., (2008). The mobility and degradation of pesticides in soils and the pollution of groundwater resources. Agr. Ecosyst. Environ., 123 (4), 247-260 (14 pages).

Babich, H.; Davis, D. L.; Stotzky, G., (1981). Dibromochloropropane (DBCP): A review. Sci. Total Environ. 17 (3), 207-221 (15 pages).

Bodaghpour, S.; Mirbagheri, S. A.; Hashemi Monfared, S. A., (2007). Introduction of a mathematical storage function model based on lumping process of infiltration theory. $2^{\text {nd. }}$ IASME/WSEAS international conference on water resources, hydraulics and hydrology, Portoroz, Slovenia, 5256 (5 pages).

Deeley, G. M.; Reinhard, M.; Stearns, S. M., (1991). Transformation and sorption of 1, 2-dibromo-3chloropropane in subsurface samples collected at Fresno, California. J. Environ. Qual., 20 (3), 547-556 (10 pages).

Huston, J. L.; Cass, A., (1987). A retentivity function for use in soil - water simulation models. J. Soil Sci., 38 (1), 105113 (9 pages).

Johnson, D. C.; Selim, H. M.; Ma, L.; Southwick, L. M; Willis, G. H., (1995). Movement of Atrazine and nitrate in sharkey clay soil: Evidence of preferential flow. Report No. 846. Louisiana State University Agricultural Center, Louisiana agricultural experimental station, Baton Rouge, Los Angeles, USA.

Jury, W. A.; Spencer, W. F.; Farmer, W. J., (1983). Behavior assessment model for trace organics in soil: I. model description. J. Environ. Qual., 12 (4), 558-564 (7 Pages).

Kah, M.; Brown, C. D., (2007). Changes in pesticide adsorption with time at high soil to solution ratios. Chemosphere, 68 (7), 1335-1343 (9 pages).

Kalita, P. K.; Ward, A. D.; Kanwar, R. S.; McCoo, D. K., (1998). Simulation of pesticide concentrations in groundwater using Agricultural Drainage and Pesticide Transport (ADAPT) model. Agr. Water Manage., 36 (1), 23-44 (22 pages).
Kloos, H., (1983). DBCP pesticide in drinking water wells in Fresno and other communities in the central valley of California. Ecol. Dis., 2 (4), 353-367 (15 pages).

Loague, K.; Bernknopf, R. L.; Green, R. E.; Giambelluca, T. W., (1996). Uncertainty of groundwater vulnerability assessments for agricultural regions in Hawaii: Review. J. Environ. Qual., 25 (3), 475-490 (16 pages).

Loague, K.; Lloyd, D.; Nguyen, A.; Davis, S. N.; Abrams, R. H., (1998). A case study simulation of DBCP groundwater contamination in Fresno County, California 1. Leaching through the unsaturated subsurface. J. Contam. Hydrol., 29 (2), 109-136 (28 pages).

McCreanor, P. T.; Reinhart, D. R., (2000). Mathematical modeling of leachate routing in a leachate recirculating landfill. Water Res., 34 (4), 1285-1295 (11 pages).

Mirbagheri, S. A., (1995). Modeling contaminant transport in soil column and groundwater pollution control. Proceeding of regional conference on water recourse management, Isfahan University of Technology. August, 279-293.

Mirbagheri, S. A.; Kazemi Esfeh, H. R., (2008). Finite element modeling of leaching from a municipal landfill. J. Appl. Sci., 8 (4), 629-635 (7 pages).

Mirbagheri, S. A.; Tanji, K. K.; Rajaee, T., (2008). Selenium transport and transformation modeling in soil columns and ground water contamination prediction. Hydrol. Proc., 22 (14), 2475- 2483 (9 pages).

Muller, T. S.; Sun, Z.; Kumar, M. P. G.; Itoh, K.; Murabayshi, M., (1998). The combination of photocatalysis and ozonolysis as a new approach for cleaning 2,4dichlorophenoxyaceticacid polutted water. Chemosphere, 36 (9), 2043-2055 (13 pages).

Oreskes, N.; Shrader-Frechette, K.; Belitz, K., (1994). Verification, validation and confirmation of numerical models in the earth sciences. Science, 263 (5147), 641-646 (6 pages).

Qasim , S. R.; Burchinal, J. C., (1970). Leaching of pollutants from refuse beds. J. sanitary Eng. div., 96 (1), 49-58 (10 pages).

Rovers, F. A.; Farquhar, G. j., (1973). Infiltration and landfill behavior. J. Environ. Eng., 99 (5), 671-690 (20 pages).

Scholtz, M. T.; Bidleman, T. F., (2007). Modeling of the longterm fate of pesticide residues in agricultural soils and their surface exchange with the atmosphere: Part II projected long-term fate of pesticide residues. Sci. Total Environ., 377 (1), 61-80 (20 pages).

Stevenson, D. E.; Baumann, p.; Jackman, J. A., (1997). Pesticide properties that affect water quality. Texas agricultural extension service, B-6050.

Taube, J.; Vorkamp, K.; Forster, M.; Herrmann, R., (2002). Pesticide residues in biological waste. Chemosphere, 49 (10), 1357-1365 (9 pages).

USDA, (2006), 2,4-D human health and ecological risk assessment, United States Department of Agriculture, Forest Service, Forest Health Protection, Final report, USDA Forest Service Rosslyn Plaza Building C, Room 7129C 1601, North Kent Street Arlington, VA 22209 September 30.

Vorkamp, K.; Taube, J.; Herrmann, R., (1997). Multiresidue analysis of pesticides and their metabolites in biological waste. In: Stentiford, E. I. (Ed.). Organic recovery and biological treatment, Zeebra Publishing, Manchester, 221225 (5 pages). 


\section{S. A. Mirbagheri; S. A. Hashemi Monfared}

Vorkamp, K.; Taube, J.; Forster, M.; Kellner, E., Herrmann, R., (1999). Pesticides as an unknown component of biological waste and its products, in: Del Re, A. A. M. et al. (Eds). XI international symposium pesticide chemistry. Cremona, Italy, La Coliardica Pavese, 153-163.

Wagenet, R. J.; Hutson, J. L., (1986). Predicting the fate of nonvolatile pesticides in unsaturated zone. J. Environ. Qual., 15 (4), 315-322 (8 pages).

Wagenet, R. J.; Hutson, J. L., (1987). LEACHM: Leaching Estimation and Chemistry Model: A process based model of water and solute movement transportation, plant uptake and chemical reactions in unsaturated zone, continuum Vol. 2, Water Resources Institute, Cornell University, Ithaca, New York ,USA.
Wagenet, R. J.; Huston, J. L.; Biggar, J. W., (1989). Simulating the fate of a volatile pesticide in unsaturated soil: A case study with DBCP. J. Environ. Qual., 18 (1), 78-84 (7 pages).

Walsh, J. J.; Kinman, R. N., (1979). Leachate and gas production under controlled moisture conditions, municipal solid waste: Land disposal. Proceedings of the $5^{\text {th. }}$ annual research symposium, EPA-600/9-79-023a, USEPA, Cincinnati, OH, $41-57$ (17 pages).

Zbytniewski, R.; Buszewski, B., (2002). Sorption of pesticides in soil and compost. Pol. J. Environ. Stud., 11 (2), 179-184 (6 pages).

AUTHOR (S) BIOSKETCHES

Mirbagheri, S. A., Associate professor, Department of Civil Engineering, K. N. Toosi University of Technology, Tehran, Iran. Email: mirbagheri@kntu.ac.ir

Hashemi Monfared, S. A., Ph.D. student of civil engineering, K. N. Toosi University of Technology, Tehran, Iran. Email:a_hashemi_m@Dena.kntu.ac.ir

This article should be referenced as follows:

Mirbagheri, S. A.; Hashemi Monfared, S. A., (2009). Pesticide transport and transformation modeling in soil column and groundwater contamination prediction. Int. J. Environ. Sci. Tech., 6 (2), 233-242. 